\title{
Gas Pressure Triggered by Helium as Driving Force in Tectonic Movements
}

\author{
Kari Hänninen \\ Department of Biological and Environmental Sciences, University of Jyväskylä, Finland
}

Copyright $\subseteq 2019$ by authors, all rights reserved. Authors agree that this article remains permanently open access under the terms of the Creative Commons Attribution License 4.0 International License

\begin{abstract}
The helium bulge in the thermosphere above the winter pole demonstrates that solar wind strips helium from the thermosphere into space. The existence of the bulge shows that helium flows from the interior of the earth replenish what the solar winds strip away. The calculations of Lord Kelvin showed that the primordial heat would have been exhausted within the first 98 million years of the earth's existence. There may be as much as 45 times more heat and helium generated by the radioactive decay of uranium and thorium in the earth's core than has been previously estimated. A plausible mechanism to trigger tectonic movements is the pressure exerted by helium as it ascends from the earth's core. In the mantle, helium pierces the rock and strips its bound water and the resulting steam intensifies the gas flow. Mathematically, the vertical thrust of gases per square meter in the asthenosphere more than equals the weight of a $100 \mathrm{~km}$ high and $1 \mathrm{~m}^{2}$ wide column of stone. Basalt in the oceanic crust diverts a major part of the upwelling flow of gas below the sea areas to horizontally push the continental plates. Only a minor part of the flow is liberated through black smokers. The combined effect of vertical lift and horizontal thrust of the gases then moves the tectonic plates. If a tectonic plate moves on one of the poles, it will accumulate ice, which causes the sea level to drop dramatically. This occurred when the movement of Antarctica on the South Pole lowered the sea level by $83 \mathrm{~m}$ from the elevation which prevailed in the early Cretaceous period 124 million years ago. Variations of the helium flow may be used as an indicator in assessing the possibility of volcanic eruptions and earthquakes.
\end{abstract}

Keywords Helium Bulge, Neutrino Problem, Uranium, Thorium, Static and Dynamic Gas Pressures, Plate Tectonics, Tethys Sea

\section{Introduction}

Helium is formed by the natural radioactive decay of uranium and thorium (and in smaller amounts from other radioactive elements), and by fusion reaction in stars. After hydrogen, helium is the second most abundant element $(23 \%)$ in the known universe.

The presence of helium as a major component in the earth's upper thermosphere and lower exosphere was first inferred in 1961 from the measurements of the Echo 1 satellite orbiting above $1000 \mathrm{~km}$ [1]. Helium is the most important compound in the attenuation of the sharpest edge of gamma- and X-rays as well as that of the extreme UV radiation from the sun and the heating of the upper thermosphere.

Helium is a low-density gas, $1.78 \times 10^{-1} \mathrm{~kg} / \mathrm{m}^{3}$ at $20^{\circ} \mathrm{C}$ [2]. Being lighter than air, helium has buoyancy in the atmosphere [3]. The principle of buoyance ensures that the least dense materials eventually find themselves layered atop the progressively denser materials. As a noble gas, helium does not react with other elements. That is why it is a so-called slippery element, escaping even from a hard stone like zircon [4].

High pressure and heat in the interior of the earth force helium to migrate into the troposphere and from there it immediately rises to the thermosphere at the same rate at which it is emitted from the ground. Finally, it escapes into space [5].

At sea level, only $5.25 \mathrm{ppm}$ of helium is measured. For this reason, it is assumed that helium would be a rare element in the earth. However, the existence of the helium bulge suggests this issue may not be as unambiguous as is believed. The helium bulge is a phenomenon in the thermosphere with much higher helium densities (as many as 20 times) over the winter pole than over the summer pole [6].

There is a reason to suspect that the tropospheric measurements fail to fully account for the amount of helium from the earth.

Helium is considered an important element in cutting-edge technology applications of medical, manufacturing, astronomical and computer devices [7]. The present demand for helium is currently so high some fear it may be exhausted at some point [8]. 
Yet some have speculated that the earth itself contains abundant sources of helium. A Norwegian and British team found a large deposit of helium close to volcanoes in Tanzania's Rift Valley. The research showed that volcanic activity releases helium from rock formations which is then trapped in more airtight deposits nearer the surface of the earth [9].

Because it is harmless, helium is thought to be an element without any environmental importance. That is why its' continuous volumetric measurement in emissions from volcanoes, geysers, black smokers and during earthquakes is not standard procedure. Measures are mainly restricted to the alteration, evolution and interpretation of helium isotopes from several geothermal systems [10]. These studies are (at least partly) fuelled by the idea that helium-3 $\left({ }^{3} \mathrm{He}\right)$ and deuterium may be potential aneutronic fuels for fusion reactors [11]. For this purpose, ${ }^{3} \mathrm{He}$ is searched for practically everywhere [12].

Recently, however, more attention has been paid to the amount of helium released during the eruptions of geysers and volcanoes. Research results from Yellowstone geysers have shown that the helium flow may be hundreds, possibly thousands, of times more than expected [13]. One reason proposed for the observed phenomenon was an accidental discharge of 'primordial' helium.

Prior to the 2011-2012 submarine eruption off the coast of El Hierro (Canary Islands, Spain), Padrón et al. [14] observed significant increases in helium emissions from the soil and in groundwater. As the volcano began to stir, the crust fractured and helium, mostly from the mantle, flowed to the surface. As the actual eruption began, gas flow at the surface increased dramatically, and gas pressure beneath the island dropped.

Tectonic movements are suggested to be caused by high internal heat and the upwelling of magma. However, heat alone cannot physically transport solid or molten material from one place to another. It causes thermal expansion to an object which stays stationary. Furthermore, it is difficult to understand how an upward movement could create a horizontal vector to push the continental plates in a horizontal direction. With the aid of gaseous medium, however, heat can transport physical objects from one place to another, just as the steam engines in the locomotives did.

Since the time of Otto von Guernike (1654), it has been known how tightly the air pressure pushes together two hollow hemispherical brass shells when the air inside is removed. The earth's interior contains extremely high pressure and temperature conditions. An important yet little discussed issue is the enormous thrust pressurized gas possess in these conditions.

The earth's crust contains 15,000 to 20,000 ppm of water and the mantle 380 to $2,560 \mathrm{ppm}$ [15]. As it pierces the stones, helium strips the bound water from the stones [16]. Under high pressure and at high temperatures water becomes steam, so the nearer the surface the gases rise, the more their volume increases. Even though the earth's internal pressure and temperature decrease, the thrust of the gas would remain relatively high.

\section{Materials and Methods}

\subsection{Aims of the Study}

The aim of this meta-study is to determine if the production of helium in the interior of the earth is sufficient to trigger tectonic movements. For this purpose, the concentration of helium in the atmosphere is considered. The pressure caused by helium in plate tectonics is calculated in the conditions prevailing in the interior of the earth. Earthquakes by tectonic movements have momentary effects, while movements on (and over) one of the poles causes a long-lasting drop (rise) in the sea level. As an example of this phenomenon, the movement of Antarctica on the South Pole since the Cretaceous Period 124 million years ago is also addressed.

This study is based on the data available regarding helium in the atmospheres of the earth and the moon and in black smokers. Discrepancies in the calculated and observed amounts of neutrinos from the sun are also discussed. The helium flow is depicted against the known structures of the continental and oceanic crusts.

\subsection{Formulas Used in Calculations}

\subsubsection{Effect of Static Pressure}

If the static pressure inside the container is $\mathrm{p}_{\mathrm{st}}$, then the gas will exert a force $F$ on the container wall (1):

$$
\mathrm{F}=\mathrm{p}_{\mathrm{st}} \times \mathrm{A}
$$

$F$ is the impact force due to gas collisions in Newtons $(\mathrm{N})$; $A$ is the area in square meters; and $p$ is the static gas pressure in pascals $\left(\mathrm{N} / \mathrm{m}^{2}\right)$

A technical atmosphere (symbol: at) is a non-SI unit of pressure equal to one kilogram-force per square centimeter. If the static pressure in pascals is known, it can be converted (at normal temperature $=293 \mathrm{~K}$ ) to kilogram-force per square meter $\left(\mathrm{kgf} / \mathrm{m}^{2}\right)$ via a calculator [17]. This makes comparison of the area density $\left(\mathrm{kg} / \mathrm{m}^{2}\right)$ of an object and the gas pressure a straightforward process.

For example, the pressure about $100 \mathrm{~km}$ below the Earth's surface (in the asthenosphere) is 13,600 atm $(1,378,020,000 \mathrm{~Pa})$ [18]. Using the calculator [17], the pressure of a gas at this depth (at $293 \mathrm{~K}$ ) is $1.41 \times 10^{8}$ $\mathrm{kgf} / \mathrm{m}^{2}$.

Charles's law states that when the pressure is constant, the volume of a gas varies directly with the temperature $\mathrm{V} \propto \mathrm{T}$ :

$$
\frac{V_{1}}{T_{1}}=\frac{V_{2}}{T_{2}}
$$

$\mathrm{V}_{1}$ and $\mathrm{T}_{1}$ are the initial temperature and volume of the 
gas, and $\mathrm{V}_{2}$ and $\mathrm{T}_{2}$ the final values, respectively. It can be seen that if the temperature is increased, the volume of the gas will increase as well. In the interior of the earth, the available free space for gas molecules is more or less constant. Then, even though the temperature increases, the gas volume cannot increase. This means that the gas pressure must increase.

Pressure, temperature and volume are connected with each other by the equation of the ideal gas law (3).

$$
\mathrm{pV}=\mathrm{nRT}
$$

Where $R$ is the gas constant $\left(8.3145 \mathrm{JK}^{-1} \mathrm{~mol}^{-1}\right)$, and $n$ is the number of gas moles

The asthenospheric temperature at a depth of $100 \mathrm{~km}$ is $1400{ }^{\circ} \mathrm{C}$ (or $1673 \mathrm{~K}$ ) [19]. Given that the mole amount of the gas $(n)$ is constant, the effective static gas pressure is $8.05 \times 10^{8} \mathrm{kgf} / \mathrm{m}^{2}$ (3). If $n$ increases 10 times, the gas pressure increases 10 times if other variables remain the same.

\subsubsection{Effect of Dynamic Pressure}

When a gas is moving, there is a second component to the pressure. It is called the dynamic pressure. It is a pressure exerted perpendicular to the direction of the flow and is represented by the symbol $\rho$. Dynamic pressure is the kinetic energy of a flowing fluid - liquid or gas per unit volume - and can be expressed as

$$
p_{d}=1 / 2 \rho v^{2}
$$

where $p_{d}$ is the dynamic pressure in pascals $\left(\mathrm{N} / \mathrm{m}^{2}\right), \rho$ is density of gas $\left(\mathrm{kg} / \mathrm{m}^{3}\right.$, or slugs in the British gravitational system) and $\mathrm{v}$ is velocity $(\mathrm{m} / \mathrm{s})$.

The total pressure is then

$$
\mathrm{p}_{\text {tot }}=\mathrm{p}_{\mathrm{st}}+\mathrm{p}_{\mathrm{d}}
$$

The force that the dynamic pressure of a hurricane generates against a wall at a temperature of $20{ }^{\circ} \mathrm{C}$, air density of $1.2 \mathrm{~kg} / \mathrm{m}^{3}$ and with a wind speed of $37 \mathrm{~m} / \mathrm{s}$ is according to (4): $\mathrm{p}_{\mathrm{d}}=1 / 2 \times 1.2 \mathrm{~kg} / \mathrm{m}^{3} \times(37 \mathrm{~m} / \mathrm{s})^{2}=821 \mathrm{~Pa}$ $\left(\mathrm{N} / \mathrm{m}^{2}\right)$.

The force acting directly on a wall with area $10 \mathrm{~m}^{2}$ is according to (1): $\mathrm{F}=\mathrm{p}_{\mathrm{d}} \times \mathrm{A}=821 \mathrm{~N} / \mathrm{m}^{2} \times 10 \mathrm{~m}^{2}=8.2 \mathrm{kN}$ which is almost the weight of a small car [20].

In terms of the dynamic pressure the steam is more important than helium. Density of steam, for example at $250{ }^{\circ} \mathrm{C}$ and under a pressure of 39.5 atm (40.8 at) is 20 $\mathrm{kg} / \mathrm{m}^{3}$ [21]. The density of helium at similar conditions is $3.65 \mathrm{~kg} / \mathrm{m}^{3}$ [22]. Under these conditions steam produces 5.5 times greater dynamic pressure than helium does. Initially in the core, the mole fraction of helium in the upwelling gas is $\sim 100 \%$, the higher up the gas is rising the more the mole fraction of steam increases. Water vapor can account for $97 \%$ or more of total gas emissions from a volcano [23].

The Antarctic ice sheet contains $3 \times 10^{7} \mathrm{~km}^{3}$ of ice [24]. The area of the earth's oceans is $3.6 \times 10^{8} \mathrm{~km}^{2}$. The amount of Antarctic ice is equivalent to an $83 \mathrm{~m}$ layer of water in the oceans.

\section{Discussion}

\subsection{Effect of Solar Wind on the Helium in the Atmospheres of the Earth and the Moon}

\subsubsection{Helium Bulge in the Atmosphere of the Earth}

In 1974, Keating and Prior [25] noted an apparent enhancement near the winter pole, which they termed the "winter helium bulge" with an approximate winter-to-summer ratio of 2.5. Later measurements by Keating et al. [26] showed ratios in excess of an order of magnitude (see Figure 1).

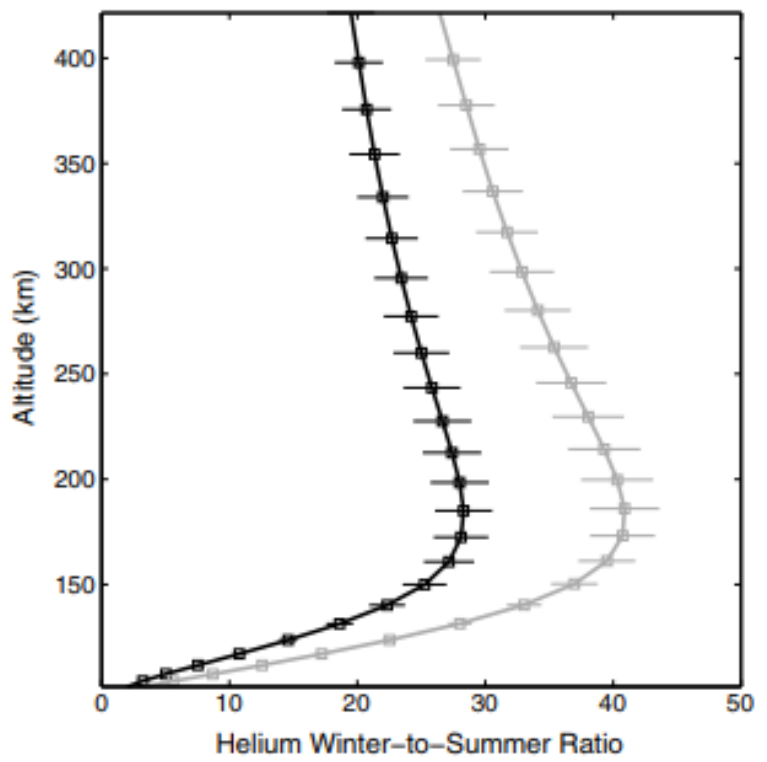

Figure 1. Vertical profile of the winter-to-summer helium bulge ratio during solar minimum June (black, 21 Jun 2008) and December (grey, 21 Dec 2008) solstice conditions, the profiles represent the daily average of the ratio of maximum-to-minimum helium number densities taken along each meridian, roughly approximating the sampling of a polar-orbiting satellite [30]

In late December 1975, the Atmosphere Explorer-D satellite measured the winter helium bulge between the perigee (about $150 \mathrm{~km}$ ) and an altitude of $650 \mathrm{~km}$. During the time the perigee was at the equator, altitudes above approximately $550 \mathrm{~km}$ were located north and south at latitudes greater than $50^{\circ}$. Helium showed, in the winter hemisphere, densities that were 20 times higher than those at corresponding altitudes and latitudes in the southern, summer hemisphere [27].

Recent findings show that solar wind picks up $\mathrm{O}$ ions from the upper thermosphere. When the earth is between the sun and moon, these ions are then carried to the moon [28]. He molecules are lighter than $\mathrm{O}$ atoms and so are more prone to ascend in the atmosphere. When they ascend high enough, they are eventually stripped away by the solar wind. 
The summer thermosphere receives most of the solar wind. The higher the latitudes are, the more the winter hemisphere is protected. For this reason, the winter helium bulge is centered around the winter pole.

According to Reber et al. [29], there is a strong correlation of the maximum helium density with the location of the winter geomagnetic pole. It is known that solar wind is sensitive to variations in geomagnetism.

The upward flow of helium is so fast that it does not have time to distribute evenly in the troposphere, stratosphere or even in the mesosphere. At an altitude of $175 \mathrm{~km}$, the helium concentration reaches its atmospheric maximum (see Figure 1). After that it is increasingly exposed to the solar wind. That is why helium vanishes much sooner than if the only factor would be its normal escape velocity from the earth.

In the thermosphere between $40^{\circ} \mathrm{N}$ to $40^{\circ} \mathrm{S}$ the solar wind strips the helium away throughout the year. High emissions of helium from hot spots such as geysers, black smokers and volcanoes may remain unnoticed because they are currently not targeted for helium measurements. It is likely that the present overall atmospheric equilibrium concentration of helium (5.25 ppm) provides a significantly underestimated picture of helium emissions on the earth.

Underestimated helium concentration means underestimated uranium and thorium concentrations in the interior of the earth as well.

\subsubsection{Helium Bulge in the Atmosphere of the Moon}

The moon has a thin layer of gases. Technically, it is an exosphere where the gases are so spread out that they rarely collide with one another. In the moon's atmosphere, there are only 100 molecules per $\mathrm{cm}^{3}$, about a thousandth of trillionth of the earth's at sea level. The total mass of these lunar gases is about 25,000 kilograms [31].

During the Apollo 17 moonwalk in 1972, astronauts deployed the Lunar Atmosphere Composition Experiment (LACE). The LACE measurements during the 1970s showed an increase in helium abundance at night. These findings were corroborated by measurements of the Lunar Reconnaissance Orbiter, which in 2012 detected helium in the moon [32].

The moon has two weeks of continuous daylight followed by two weeks of continuous darkness. The nightside is protected from the solar wind, so then the helium outgassed from the interior is able to accumulate. The moon has a weak, non-protecting magnetic field and during the daytime the solar wind directly hits the helium and strips it away. The fact that after 4.5 billion years helium continues to be emitted from the interior implies that there is uranium and thorium in the core of the moon.

\subsection{Solar Neutrino Problem Suggests the Presence of Uranium and Thorium in the Sun}

The detected number of neutrinos from the sun to the earth is only one third of the number predicted by the Standard Solar Model (SSM), the mathematical model used to calculate neutrinos from the sun, which treats the sun as a spherical ball of gas [33].

The discrepancy may be due to the fact that the sun does not consist entirely of gas, but it contains considerable amounts of uranium and thorium. Fission produces $0.7 \mathrm{MeV}$ energy per unit mass whereas fusion reaction produces $6.2 \mathrm{MeV}$ per unit mass [34]. Neutrinos have a small mass, so according to Einstein's mass-energy equation, $\mathrm{E}=\mathrm{mc}^{2}$, they also have energy. Being less energetic, the fission reaction generates fewer neutrinos than a fusion reaction does.

Because part of the sun's energy is produced by fission, there are fewer proton-proton interactions and less production of solar neutrinos than is assumed in the SSM calculations. A corollary of this hypothesis is that helium in the sun is formed both via fusion and fission reactions.

The protostar from which the Solar System was formed had to contain uranium and thorium as well. This means those compounds would exist in every planet and moon in our Solar System, including meteorites, therefore it is unsurprising that the thorium/uranium ratio in meteorites is 3.53 [35] and in bulk silicate Earth it is 4.2 [36].

\subsection{Internal Heat of the Earth and the Moon}

\subsubsection{Moon's Internal Heat}

More than 30 years after the Apollo experiments, it was confirmed that the lunar core is in a liquid state and that it has a radius of 365 kilometers [37]. Because the moon now has an extremely weak magnetic field, it is likely that liquid iron does not contain enough electrons to induce a substantial magnetic field for (any) celestial body. Iron most likely needs to be in the plasma state. Then it contains considerably more free electrons than in a liquid state [38].

A sample of the moon rocks Apollo astronauts brought back have demonstrated that a powerful magnetic field surrounded the moon billions of years ago. New research on the Apollo data shows that this ancient magnetic field lasted for more than a billion years. At one point, it was at least as strong as the field generated by the modern earth [39].

During the first billion years, the heat from the uranium in the core could keep some iron in a plasma state. After the first billion years, the $25 \%$ reduction in the amount of uranium lowered its energy production. Subsequently, the amount of iron in the plasma state decreased so much that there were no longer enough free electrons to provide a strong magnetic field. A second critical issue was the slowing of the moon's rotation around its axis due to the tidal friction by the earth. These two factors weakened the magnetic field of the moon so much that after the first billion years it was not strong enough to leave strong marks on the stones.

The interior temperature of the moon was measured by 
electromagnetic sounding during the Apollo 15 mission. Up to a depth of at least $500 \mathrm{~km}$, it was below $1000{ }^{\circ} \mathrm{C}$. The melting point is at a depth between 800 and $1500 \mathrm{~km}$. [40]. Stones start melting at $600{ }^{\circ} \mathrm{C}$ [41]. The temperature gradient in the moon is 1.33 and the maximum core temperature would be $2300{ }^{\circ} \mathrm{C}$.

\subsubsection{Earth's Internal Heat}

According to present estimates, the maximum core temperature of the earth is $5000{ }^{\circ} \mathrm{C}$ [42], meaning the earth's would be only two times warmer than the moon's. As the mass of the moon is only $1.2 \%$ that of the earth, one would expect a difference greater than only $50 \%$. It is likely that the internal heat of the earth has been underestimated.

The earth's interior temperature increases steadily as a function of its depth (see Figure 2). The geothermic gradient is $3.5^{\circ} \mathrm{C} / 100 \mathrm{~m}$. Let us suppose that this gradient would be constant throughout to the centre of the earth, even though it would be an underestimate because the heat conductivity of iron is ten times greater than that of stone [43]. The maximum core temperature would be $6,370 \mathrm{~km} \times$ $35{ }^{\circ} \mathrm{C} / 1 \mathrm{~km} \sim 223,000{ }^{\circ} \mathrm{C}$. At this temperature, matter is already in the plasma state [44]. Part of the iron would also be in a plasma state, providing enough free electrons to create a substantial magnetosphere.

Primordial heat, generated during the aggregation stage of the earth, is considered an important source of heat even today. It is presumed that once the mantle became mostly solid, the removal of this heat became sluggish and inefficient [45].

This reasoning relies on the assumption that stone in the mantle, being an excellent insulator, would conduct heat only $400 \mathrm{~km}$ in 5 billion years. On the other hand, all stones studied to date can be considered moderate heat conductors [46], which is why fireplaces are made from stones. Suppose one to build a fireplace from mantle stone using 5 $\mathrm{cm}$ thick bricks. Heating it up would require 625 years. It is obvious that the heat conductivity of mantle rocks has been underestimated.

Based on calculations of the earth's cooling rate, assuming a constant heat conductivity, and a thermal gradient of $1{ }^{\circ} \mathrm{F}$ per 50 British foot $\left(\sim 0.56{ }^{\circ} \mathrm{C} / 15,3 \mathrm{~m}\right.$ or $\sim 3.6^{\circ} \mathrm{C} / 100 \mathrm{~m}$ ), Lord Kelvin [47] estimated the age of the earth to be 98 million years. This conclusion was wrong, but the time span of 98 million years can be considered a rough estimation of the effective duration time of primordial heat. The current prevailing theory overestimates its importance by a factor of 45 . The only possible additional means of heating over time would be the radioactive decay of a substantial amount of uranium and thorium. Their amount in the core is 45 times greater than what has been estimated. This means that the formation of helium has been similarly underestimated.

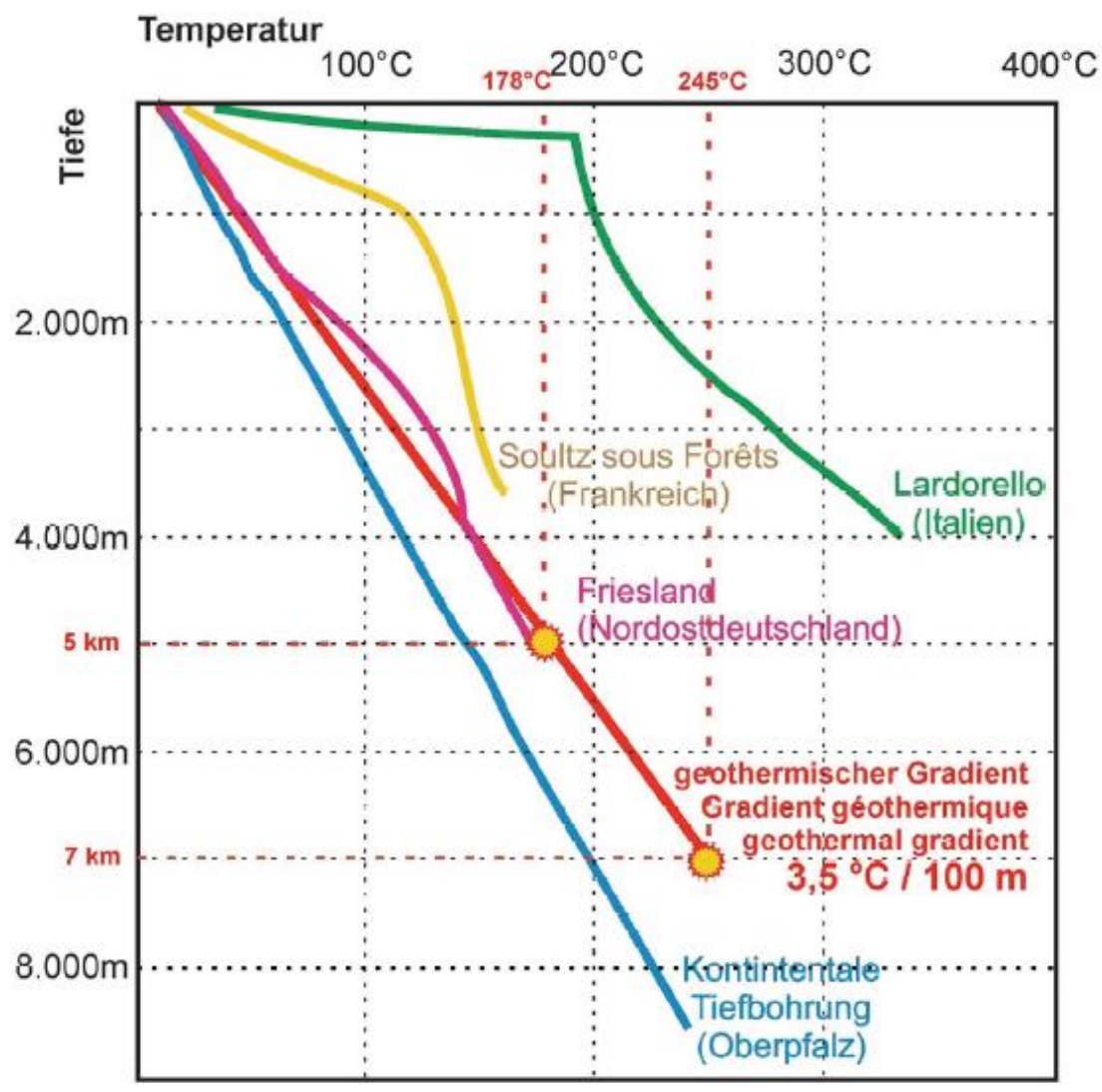

Figure 2. Thermal gradients of ground to the depth of $9 \mathrm{~km}$ in the Middle Europe. Red line describes the average of Earth [48] 


\subsection{Structure of the Continental and Oceanic Crusts}

The earth is covered by a bimodal distribution of thin oceanic crust $(5-15 \mathrm{~km})$ and thick continental crust (30-70 $\mathrm{km}$ ) (see Figure 3). The average continental crust is andesitic/granitic in composition while the oceanic crust is mainly basalt and gabbro. The andesitic/granitic continental crust appears to be unique within our Solar System. The oldest areas of continental crust are $\sim 4$ Ga old, with single zircon crystals as old as $\sim 4.4 \mathrm{Ga}$. The oldest oceanic crust is less than 250 Ma old [49].

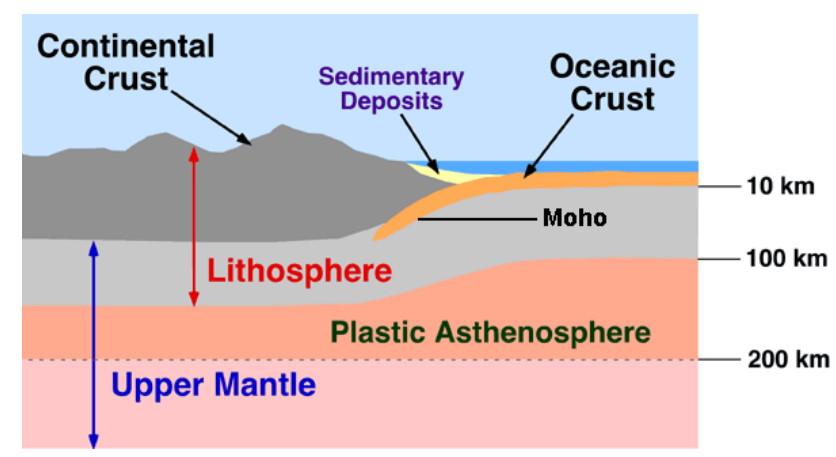

Figure 3. Details of the crust and mantle at the edge of a continent, also shown are the lithosphere and asthenosphere [51]

Below the continental tectonic plates is the lithosphere, which itself rests above the fluid-like (visco-elastic solid) asthenosphere on which the continental plates move (see Figure 3). The majority of research shows that the tectonic plates move at average rates between approximately 0.60 $\mathrm{cm} / \mathrm{a}$ to $10 \mathrm{~cm} / \mathrm{a}[50]$.

Basalt has a toughness of 2.3 and a hardness of 8 in the Mohs scale, whereas granite has values of 1.5 and 7 , respectively. Andesite has a composition that is intermediate between basalt and granite. The values of gabbro are somewhat lower those of granite.

Gas is considered 'lazy,' meaning it always moves along the easiest route. It is likely that if more than one route is available, helium would probably travel through the granite/andesite layer than through the basalt layer.

\subsubsection{The Continental Crust}

Based on the measurements of the velocities of seismic waves, the continental crust is thought to be composed of three layers with a different structure. The upper layer is suggested to be a granite layer (sial). The intermediate layer is generally thought to have a mafic composition (sima). The boundary between this intermediate layer and the mantle (or the lower layer) is the Moho [52].

Jones [53], using a collocated magnetotelluric (MT) study, proposed a more detailed model for the continental crust. It includes a resistive upper crust, a rather conductive layer in the middle crust and a moderately conductive layer in the lower crust (see Figure 4). Jödicke [54] suggested that the origins of the highly conductive layers proposed by Jones are in water and graphite.

\subsubsection{The Oceanic Crust}

In contrast to the thick, buoyant continental crust, the oceanic crust is comparatively thin and dense. The ocean crustal structure is astonishingly uniform. This implies that the process which creates it must also be uniform. It is thought to be comprised of up to four layers (see Figure 5).

The structure of the uppermost layer (Layer 1) is interpreted as sediments. Layer 2 represents the volcanic basalt basement. This upper crust layer is best modeled as a zone of rapidly increasing velocities. In some cases, a thin zone with lower velocity gradients caps the uppermost crust, which is now presumed to represent Layer $2 \mathrm{~A}$. Layer 3 is thought to be the major part of the oceanic crust, with an average depth of $4.6 \mathrm{~km}$. It consists mainly of gabbro. Below it is the Moho zone and, broadly interpreted, the uppermost mantle, which contains the lithosphere, asthenosphere and the proper upper mantle [52].
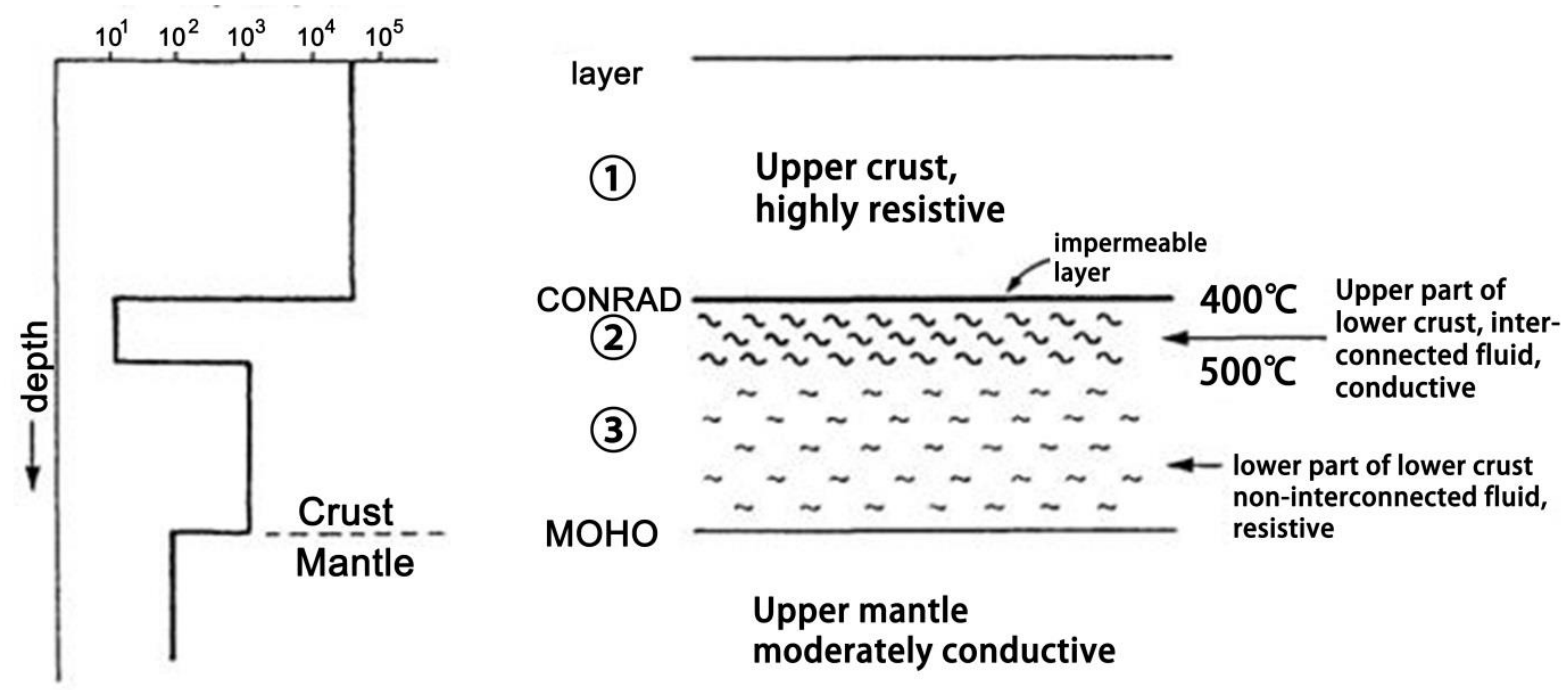

Figure 4. General model of the continental crust with a resistive upper crust underline two layers of conductive crust by Jones [53] 


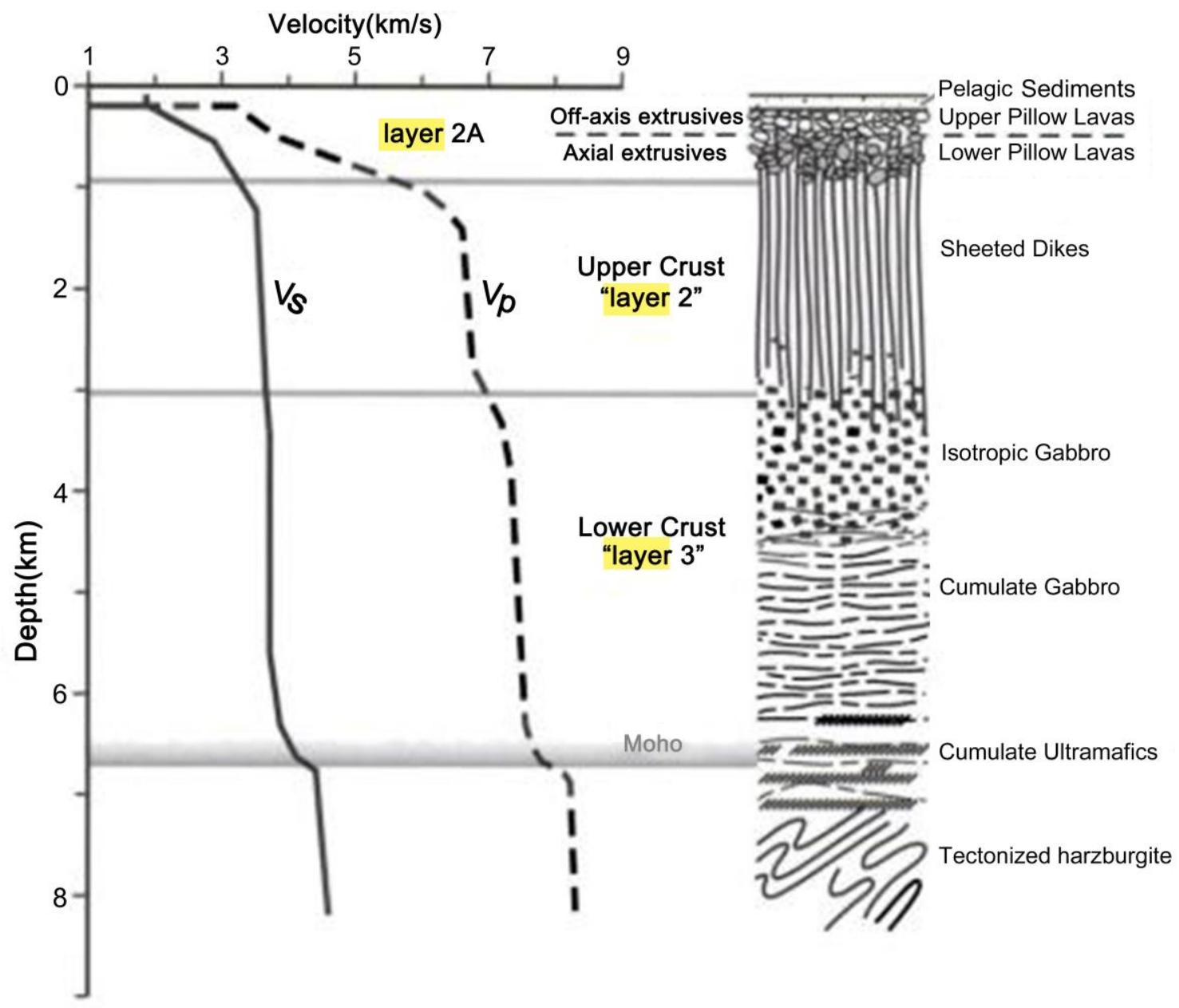

Figure 5. The seismic structure of the Pacific Ocean crust [52].

\subsection{Current Theory of the Mechanism of Plate Tectonics}

In the current theory, it is presumed that the interior heat of the earth is the main reason for plate tectonics. It would cause convections in the core-mantle boundary (CBM) at a depth of 2,900 km. These convections would further force the continental plates to move. As a closer mechanism, it has been suggested that buoyance would drive these convections. One source of buoyancy is generated by the exclusion of incompatible light elements from the solid, whereas the other is due to latent heat release [45].

At the pressure of the CBM, the liquid appears to be $3 \%$ to $4 \%$ denser than the mineral [55]. If the volume increases or decreases by $3 \%$, the height would increase or decrease by $1 \%$. If density changes take place within a $200 \mathrm{~km}$ zone, the change in height would be $2 \mathrm{~km}$. This increase would influence a vertical thrust.

However, the convections would not necessary occur selectively under the continents. They would rather be distributed in the proportion of 30 to 70 under the continents and oceans respectively. It is difficult to see how there would be generated horizontal thrust which could move the continental plates.
It is well known that Newcomen's steam engine, from 1712 , was ineffective ( $1 \%$ to $2 \%$ ) because the liquefaction of steam consumed much of the released latent heat. The Watt steam engine from 1765 was much more effective because it featured a separate steam condenser. The Watt engine consumed $75 \%$ less fuel than Newcomen's. In the interior of the earth there are no separate condensers, so latent heat would be a highly ineffective method of producing energy.

Convection from the molten magma would carry the heat from the CBM upward effectively, and heating the returning cooled magma in the CBM would effectively consume the heat as well. The interior of the earth would have cooled eons ago if this mechanism had occurred.

\subsection{Pressure of Helium as a Trigger of Plate Tectonics}

\subsubsection{Ocean Crust Diverts Upwelling Helium to Flow Horizontally}

If it were assumed that helium ascends rather uniformly throughout the earth's surface, $70 \%$ of it would be emitted through the oceans and the other $30 \%$ through the continents. The amount of helium flow through the oceanic 
crust should therefore be 2.33 times greater than the flow through the continental crust. However, the volcanic activity distribution is overwhelmingly concentrated on land areas [56] (see Figure 6.)

The injection of ${ }^{3} \mathrm{He}$ into the ocean waters is shown to occur mainly along mid-ocean ridges, that is, at sites of active mantle upwelling and at mantle plume hot spots (e.g. Hawaii and Iceland) [57]. In the deepest part of the Pacific Ocean there is actually little helium, even an order of magnitude less than in the hot spots. It is clear that helium encounters difficulties in penetrating the oceanic crust (see Figure 7).

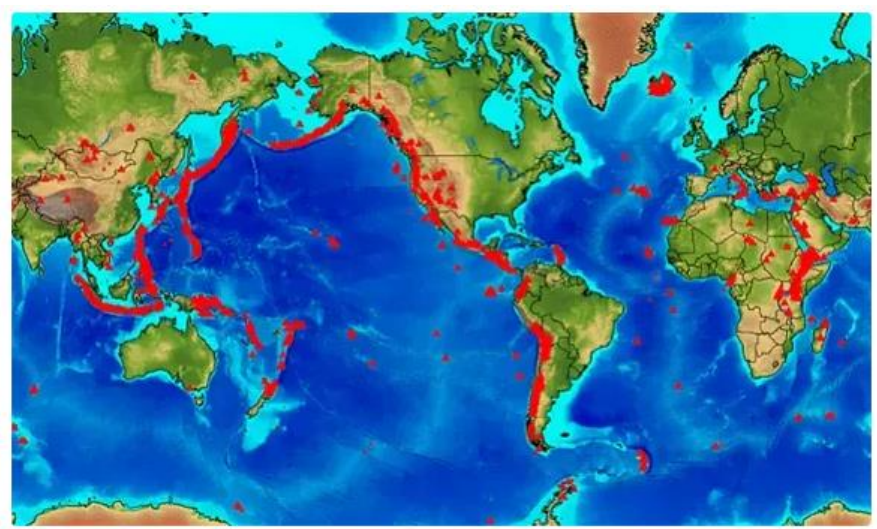

Figure 6. Distribution of volcanic activity on the earth [56]
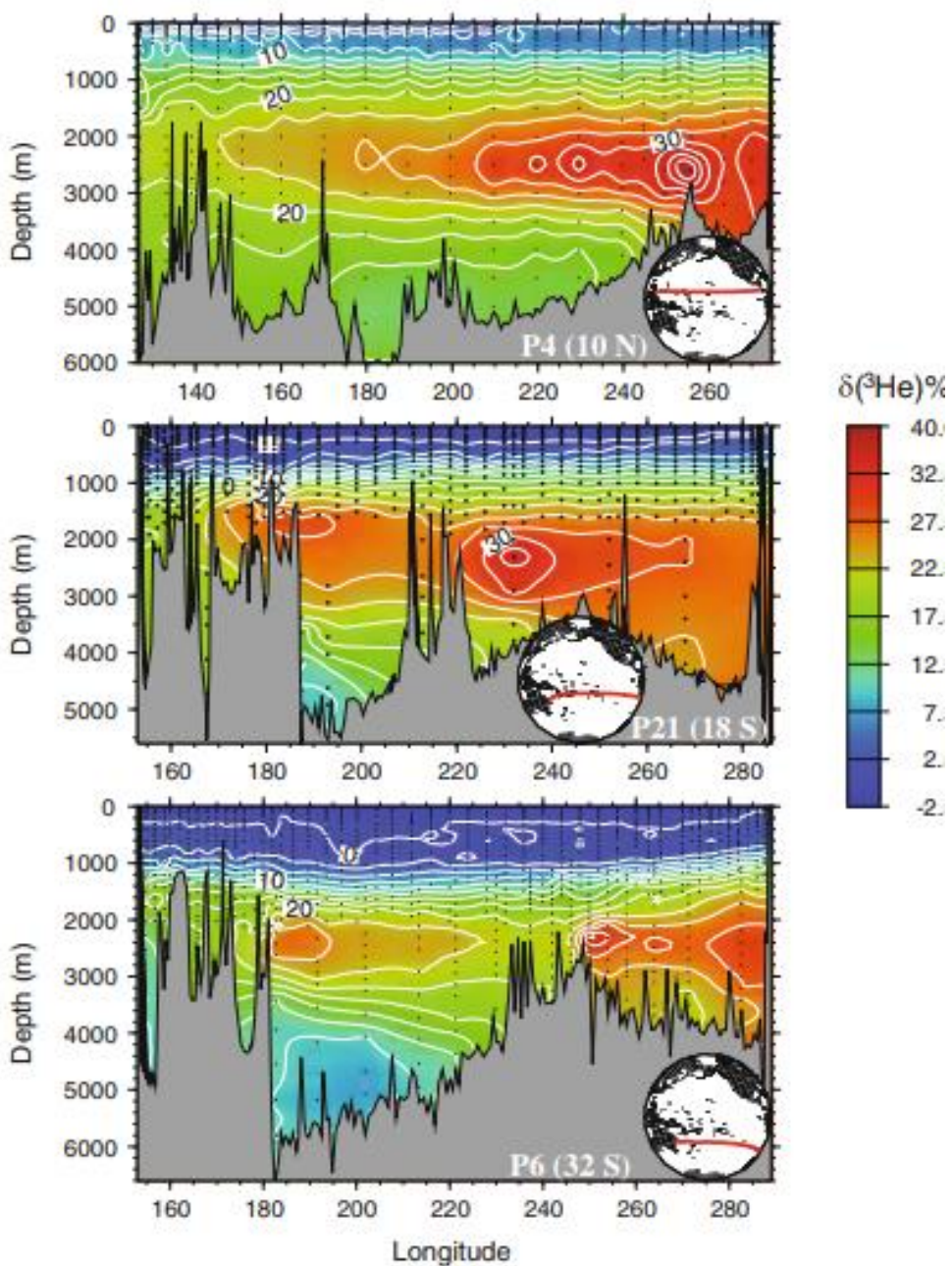

Figure 7. Zonal distributions of ${ }^{3} \mathrm{He}$ at three latitudes in the Pacific Ocean, the values presented are the dissolved helium ${ }^{3} \mathrm{He} /{ }^{4} \mathrm{He}$ isotope ratio anomaly in percent relative to the atmospheric ratio [57] 


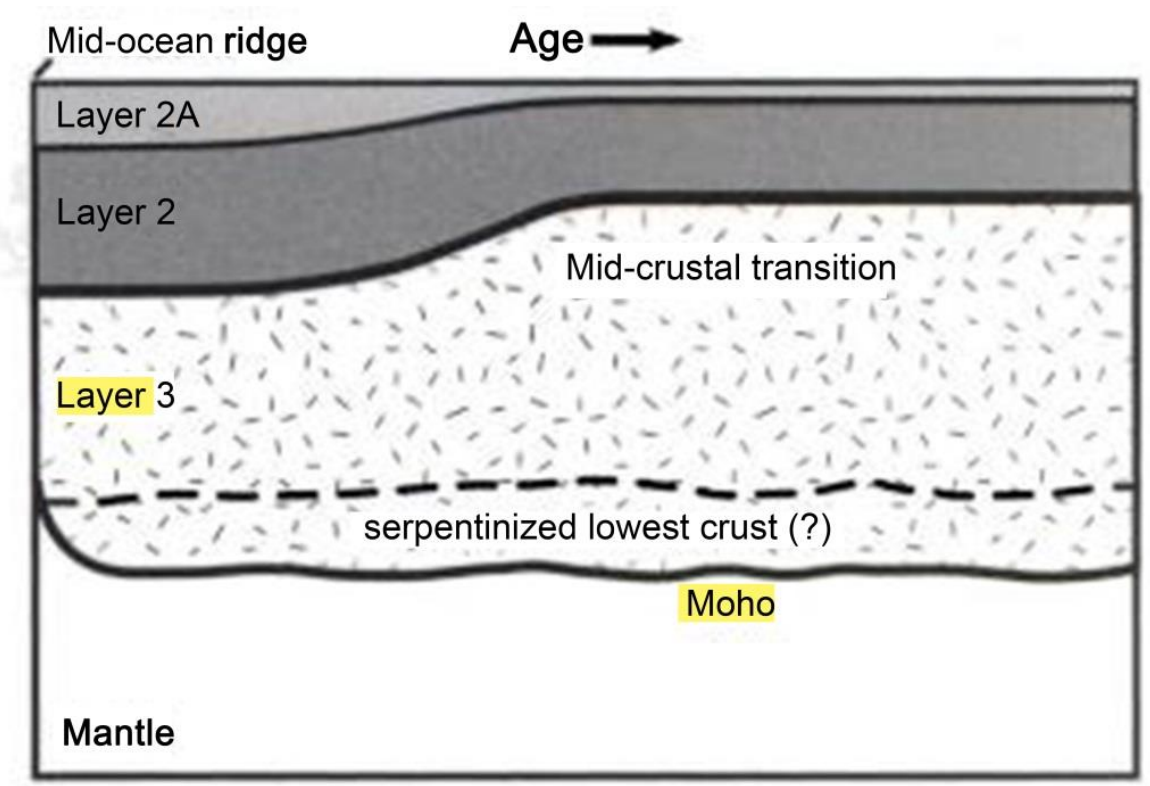

Figure 8. Schematic presentation of the long-term evolution of the ocean crust, layer $2 \mathrm{~A}$ thins significantly and Layer 3 appears to thicken because the seismic velocities increase in Layer 2. The rocks at the base of Layer 2 take on Layer 3-like velocities. The Moho changes little [52]

Seismic velocity measurements regarding oceanic crusts of varying ages show that Layer $2 \mathrm{~A}$ thins significantly over time (see Figure 8). It was attributed to the mineral precipitation in the porous extrusive rocks of the uppermost crust by way of water circulation [58]. Davis et al. confirmed that the hydrothermal circulation continues in crust that is several million years old [59].

Basalt in Layer 2 likely directs some of the upwelling helium and the steam it has stripped to flow in a horizontal direction. Some of the helium eventually penetrates Layer 2. Nearer the surface pressure and temperature are lower, so Layer $2 \mathrm{~A}$ is probably tight enough to divert the flow of gases in the horizontal direction as well.

Helium likely has a minor gas component at these stages. Steam is likely the major component. It would be correct to say that there is now a hydrothermal flow in question. Over time, these continuous flows consume the lower part of Layer 2 to a small degree, and that of Layer 2A substantially.

\subsubsection{Interactions of the Upwelling Helium with the Mantle and Crustal Rocks}

Black smokers emit helium along with methane and hydrogen [60]. It is likely that a major portion of the hydrogen produced in the subsurface is not consumed before venting. The total production of methane and hydrogen is calculated to be about $20 \times 10^{9} \mathrm{~mol} \mathrm{a}^{-1}$ and 190 $\times 10^{9} \mathrm{~mol} \mathrm{a}^{-1}$ respectively [61].

Interestingly, Boschetti et al. [62] did not find hydrogen in the emissions from hyperalkaline springs in Genova, Italy. The oceanic crust represents a shorter route than through the continental crust. There needs to be a mechanism that consumes the hydrogen during a longer trip.
According to Chi and Landahl [63], the reaction of hydrogen with graphite produces methane and acetylene as the predominant products. The methane-producing reaction has an activation energy of $24.2 \mathrm{kcal} /(\mathrm{g} \times$ mole $)$ while that of the acetylene-producing reaction has 47.8 $\mathrm{kcal} /(\mathrm{g} \times$ mole) [63]. It is likely that in nature selection overwhelmingly tends towards the formation of methane due to its low activation energy threshold.

In the upper mantle there is graphite which is not necessarily converted into diamond. It may have been there for billions of years [64]. According to Jödicke (1992) [55], in the continental crust, there may be graphite in as many as two layers. It is likely that hydrogen moving through the continental crust has more chances to react with graphite and convert to methane than does the hydrogen which moves through the oceanic crust.

It is likely that hot iron (or hot metals in general) abstracts oxygen from water molecules in the mantle [65]. This means that part of the steam that helium strips from the mantle rocks while piercing them is converted to $\mathrm{O}_{2}$ and $\mathrm{H}_{2}$ gases. Because 2 moles of $\mathrm{H}_{2} \mathrm{O}_{(\mathrm{g})}$ produces 2 moles of $\mathrm{H}_{2}$ and 1 mole of $\mathrm{O}_{2}$, the volume of the gas flow is additionally intensified.

\subsubsection{Horizontal Push inside the Continental Crust}

The gas flow diverted by Layer 2 in the oceanic crust pierces the granite/andesite continental crust. There it likely creates the moderately conductive layer of the lower crust.

The gas flow diverted by Layer $2 \mathrm{~A}$ which contains a significant amount of steam (because abstraction of oxygen from $\mathrm{H}_{2} \mathrm{O}_{\mathrm{g}}$ in the middle crust temperature conditions may not be possible) probably creates the rather conductive layer of the middle crust. 
These gas flows may actually pass through the entire continental crust, which would intensify the effect of the horizontal push. Even though the asthenosphere is partly liquid, and there is substantial vertical lifting from below (see section 3.6.4), the movement of the continental plates has to overcome an enormous amount of friction. It is likely that the major part of the helium which upwells below the sea area is diverted horizontally. It guarantees that the horizontal gas flow possesses enough thrust to move the tectonic plates.

Convective heat transfer by gases may be 100 to 1000 times less than that of the molten magma and metals, except for in the upper mantle and especially in the crust where the gas flow contains a significant amount of steam. However, the internal heat of the earth at the core and in the main part of the mantle is consumed only a little due to the convection by helium.

\subsubsection{Amount of the Vertical Gas Pressure (Lift) on the Continental Plates}

The pressure of the earth's outer core at the CBM boundary is 1.5 million atmospheres [66]. According to [17] the helium gas there exerts on an area of $1 \mathrm{~m}^{2}$ a thrust of $1.55 \times 10^{10} \mathrm{kgf} / \mathrm{m}^{2}$ when calculated at the temperature of $293 \mathrm{~K}$. If the CBM temperature is 10 times greater (2930 $\mathrm{K})$, the effective thrust would be ten times greater as well. Under this kind of thrust, helium pierces solid rocks and strips some of their bound water as steam. So, while ascending, and even though the pressure and the temperature are decreasing, the number of gas moles, $n$ in equation (3), increases and keeps the pressure high.

The density of the lithosphere is estimated to be 2,700 $\mathrm{kg} / \mathrm{m}^{3}$, and that of the crust is $2,670 \mathrm{~kg} / \mathrm{m}^{3}$. The weight of a lithospheric/crust column with a height of $100 \mathrm{~km}$ and an area of $1 \mathrm{~m}^{2}$ is $1.0 \times 10^{5} \mathrm{~m} \times 1 \mathrm{~m}^{2} \times 2.7 \times 10^{3} \mathrm{~kg} / \mathrm{m}^{3}=2.7 \times$ $10^{8} \mathrm{~kg}$. Subsequently the downward pressure would be 2.7 $\times 10^{8} \mathrm{kgf} / \mathrm{m}^{2}$. The effective upward gas pressure prevailing there is $8.05 \times 10^{8} \mathrm{kgf} / \mathrm{m}^{2}$ (See section 2.2.1). Mathematically, it is more than equals the downward pressure created by this $100 \mathrm{~km}$ column.

As the mole fraction of the slippery helium all the time strongly decreases and that of the steam increases, the thrust of the upwelling gases is not constant for even every square kilometre of the continental plate. In some places the gas flow may be greater, and in other places less. Places in which this thrust is high are places with a high probability of volcanic eruptions.

\subsection{Hydrothermal Vents}

\subsubsection{White and Black Smokers}

There are several thousand continuously active hydrothermal vents along the sea bottom. Many of them are located on slow spreading ridges [67], but they are also found in rather deep waters [68]. Black smokers are hydrothermal vents, chimneys formed from deposits of iron sulfide, which is black. White smokers are formed from deposits of barium, calcium, and silicon, which are white [69].

The helium flow through the hydrothermal vents reduces the lateral flow inside the oceanic crust which pushes the continental plates into horizontal movement. This may be important in slowing down the speed of the tectonic movement, and so the strength of earthquakes.

\subsubsection{Geysers}

Most geysers on the earth are concentrated in Yellowstone National Park (United States), Geyser Valley (Russia), and El Tatio (Chile). Generally, all geyser field sites are located near active volcanic areas. However, the stratovolcanoes in El Tatio geyser field have no history of volcanic eruptions. Eruption cycles of geysers range from 90 seconds, such as El Jefe (Chile) [70], to a few weeks, such as Steamboat Geyser in Yellowstone.

It is likely that the accumulation of water determines the length of the cycle. Once the underground ducts are filled, the gas pressure (triggered by helium) eventually increases until eruption occurs. Unfortunately, there are no helium measurements available for this phenomenon. Water can only slow down the helium flow, so between the eruptions there would be some helium flowing, and during eruptions there should then be more helium.

\subsection{Environmental Impacts Caused When a Tectonic Plate Moves on One of the Poles}

Based on the age of the oceanic crust, it can be estimated that over a period of 250 million years the tectonic plates move over the whole area of the oceans. It is likely that all the present continents in their tectonic movements have moved over the North Pole or the South Pole. At these moments, the continents enter an ice age. Subsequently, all of the continents show marks of glaciation. Accumulation of ice on a continent causes the sea level to drop.

If the continental shelves are considered land, the percentage of land and ocean areas is equal [42]. In order for the continental shelfs to be fully exposed, the sea level needs to drop by approximately $180 \mathrm{~m}$. This is possible when both the South and North Poles are covered by continental areas having an area of approximately 16 million $\mathrm{km}^{2}$ under the ice sheets (comprising both $\sim 3.5 \times$ $10^{7} \mathrm{~km}^{3}$ of ice).

\subsubsection{Movements of Antarctic Plate during the Last 124 Million Years}

Shallow seas are considered typical to the Cretaceous period [71]. It is likely that during that time there was no ice in Antarctica.

All of Antarctica, except the Antarctic Peninsula, is today inside the Antarctic Circle. We may so take 47 latitudinal degrees $(\sim 5200 \mathrm{~km})$ as a rough diameter of Antarctica. At present, the Antarctic plate is moving north 
into the Atlantic Ocean at a speed of 1.2 to $1.4 \mathrm{~cm} / \mathrm{a}$. It started to subduct beneath South America plate 14 million years ago in the Miocene epoch [72].

Assuming that before it collided with the South American plate, it was moving south at a speed of $5 \mathrm{~cm} / \mathrm{a}$ (500 km in ten million years), it can now be estimated that in the early Cretaceous period (at the beginning of the Aptian subdivision), 124 million years ago Antarctica was located in the Pacific Ocean between the latitudes $15^{\circ} \mathrm{S}$ and $62^{\circ} \mathrm{S}$. In order to reach its present location, it had to move $5,700 \mathrm{~km}$ to the south.

The proper ice sheet of Greenland starts at around $62^{\circ} \mathrm{N}$. It is likely that the southern hemisphere the accumulation of ice also started when Antarctica passed the $62^{\circ} \mathrm{S}$ latitude towards the South Pole.

By the early Neogene period (18 million years ago) [73], Antarctica was between $62^{\circ} \mathrm{S}$ (on the Pacific side) and $71^{\circ} \mathrm{S}$ (on the Atlantic side). Then it more or less contained the present volume of ice, and the sea level was dropped by 83 $\mathrm{m}$.

\subsubsection{Death of the Saharan Whales Corroborates the Timing of the Movements of Antarctica}

The Basilosaurus whales found in the Wadi al Hitan area (Sahara, Egypt) [74] died during the late Eocene epoch 37 million years ago [75]. By then, Antarctica had moved $4,350 \mathrm{~km}$ towards the South Pole. It was then located between the latitudes of $54^{\circ} \mathrm{S}$ (on the Pacific side) and $79^{\circ} \mathrm{S}$ (on the Atlantic side). Of the area of Antarctica 39 latitudinal degrees, was over the $62^{\circ} \mathrm{S}$ latitude. From its area $39 / 47 \times 100 \%=83 \%$ was then covered by ice sheets. This means, that due to the accumulation of ice the sea level was then dropped by $\sim 69 \mathrm{~m}$.

The Tethys Sea over the present Sahara was probably already before that isolated from the Mediterranean Sea being so an inland sea. Then further drop of the global sea level ( $0.8 \mathrm{~m}$ in a million years) due to the accumulation of ice on Antarctica did not have influence on its water level.

In a hot and possibly also in a relatively dry climate the Tethys Sea (in the Eastern Sahara) may not have received enough water from its catchment basin to compensate for the water loss due to evaporation. Through this process, a drop of $0.8 \mathrm{~m}$ in the water level may have occurred in 10,000 to 100,000 years. The subsequent increase in the water's salt content may have been fatal to the whales. Ultimately, the overly high salt concentration would have disrupted the whales' natural osmoregulation process, the excretion of urine [76]. It is possible that the excess salt concentration which finally killed the whales may have formed even over a few years' time.

\subsection{Dynamic Pressure Caused by Steam Triggers Volcanic Eruptions and Tsunamis}

The main contribution of helium is to free water as steam from the rocks. However, the more the mole fraction of steam increases relative to helium, the more difficulties steam encounters in following the path of helium. $\mathrm{H}_{2} \mathrm{O}_{(\mathrm{g})}$ is not at all as slippery as helium. Due to this, at certain locations steam may encounter obstacles which stagnate its flow while helium is still able to flow. At these points, the total pressure due to the steam is gradually growing.

It is likely that steam accumulates under a volcano until the total pressure is so high that fractures form in the crust material above. This allows steam to flow upwards. The flow rapidly gains speed, and the dynamic pressure increases so much that an eruption occurs.

In a pyroclastic flow of volcanic eruptions, the average speed is $100 \mathrm{~km} / \mathrm{h}(27.8 \mathrm{~m} / \mathrm{s})$, but the maximum speed may be even $700 \mathrm{~km} / \mathrm{h}$ or $194 \mathrm{~m} / \mathrm{s}$ [77]. Steam at $370{ }^{\circ} \mathrm{C}$ and a pressure of 210 bar (214 at) has a density of $200 \mathrm{~kg} / \mathrm{m}^{3}$ [21].

Steam advancing in these conditions at a speed of 194 $\mathrm{m} / \mathrm{s}$ is creating a dynamic pressure, which equals the force of $37,600,000 \mathrm{~Pa}\left(\mathrm{~N} / \mathrm{m}^{2}\right)$ in an area of $10 \mathrm{~m}^{2}(4)$. The force is 4,600 times stronger than that of a hurricane having a speed of $37 \mathrm{~m} / \mathrm{s}$ (see Section 2.2.2).

In a tsunami, the accumulation of the total pressure probably takes place along long lines. It would cause more or less long fractures in the layer of $2 \mathrm{~A}$ of the ocean crust. Fractures allow the steam to move upwards and rapidly gain speed.

Due to the dynamic gas pressure, the total pressure may momentarily increase so high that even a 40-meter rise of the sea bottom along a $1,500 \mathrm{~km}$ distance takes place, as occurred in the Indian Ocean tsunami in 2004 [78].

\section{Conclusions}

The solar neutrino problem demonstrates the presence of uranium and thorium in the sun. Their radioactive decay produces helium in addition to stellar nucleosynthesis. The presence of helium in the atmosphere of the moon indicates the presence of uranium and thorium in its core as well.

The helium bulge is a phenomenon in the thermosphere of much higher helium densities over the winter pole than over the summer pole. During the winter, it is protected from the solar wind, which subsequently cannot strip the helium away. Solar wind causes helium to vanish from the earth much sooner than if the only factor would be its normal escape velocity from the earth.

The calculations of Lord Kelvin showed that the primordial heat would have been exhausted within the first 98 million years. Estimates of the amount of heat (and of helium) generated by the radioactive decay of uranium and thorium in the earth's core may be as many as 45 times smaller than the actual amount.

With simple calculations it is not possible to explain all aspects of the motions of tectonic plates. However, they give estimates for the effects of the dynamic and static gas 
pressures inside the earth.

The earth's high internal pressure and heat force helium to ascend. The gas flow intensifies as helium strips water gas from the mantle rocks along with it. The high temperature of the mantle means metals are able to abstract oxygen from some of the steam. The resulting $\mathrm{O}_{2}$ and $\mathrm{H}_{2}$ additionally intensify the gas volume. Under continents, the vertical thrust of the gases per square meter more than equals the weight of a $100 \mathrm{~km}$ deep and $1 \mathrm{~m}^{2}$ wide column from the asthenosphere up to the surface. The basalt of the oceanic crust diverts the helium flow to push the continental plates horizontally. The vertical and horizontal thrusts together cause the plate tectonics. Part of the vertical thrust is freed via volcanic eruptions.

The movement of a tectonic plate over one of the poles causes ice to accumulate and a long-lasting drop in the sea level. The movement of Antarctica on the South Pole lowered the sea level by $83 \mathrm{~m}$ from the elevation which prevailed in the early Cretaceous period 124 million years ago. Variations in helium flows from the ground may be used as an indicator in assessing the possibility of volcanic eruptions and earthquakes.

\section{Acknowledgements}

I am very grateful to Matthew Wuethrich from the University of Jyväskylä Language Services for revising the English of the manuscript. I thank my wife Ritva for her support.

\section{REFERENCES}

[1] M. Nicolet, Helium, an important constituent in the lower exosphere, Journal of Geophysical Research, Vol. 66, 2263-2264, 1961. DOI: 10.1029/JZ066i007p02263).

[2] https://www.lenntech.com/periodic/elements/he.htm.

[3] J. E. Harriman, On the Buoyancy of a Helium-Filled Balloon, Journal of Chemical Education, Vol 82, No. 2, 246, 2005. DOI: 10.1021/ed082p246.

[4] W. R. Guenthner, P. W. Reiners, R. A. Ketcham, L. Nasdala, and G. Giester, Helium diffusion in natural zircon: Radiation damage, anisotropy, and the interpretation of zircon (U-Th)/He thermochronology, American Journal of Science Vol. 313, No. 3, 145-198, 2013. DOI: 10.2475/03.2013.0.

[5] https://www.lenntech.com/periodic/elements/he.htm.

[6] U. von Zahn, Early Aeronomy Results from the Satellite ESRO 4, pp. 133-157. In: B. M. McCormac (Ed), Atmospheres of Earth and Planets, D. Reidel Publishing Co., Dodrecht, Holland, 1975. ISBN: 90-277-0575-5.

[7] http://summitsourcefunding.com/blog/helium-uses-technolo gy/.
[8] E. Siegel, The World Is Wasting Our Irreplaceable Helium, And Nobody Cares https://www.forbes.com/sites/startswit habang/2017/05/26/the-world-is-wasting-our-irreplaceable -helium-and-nobody-cares/\#2491ece2132b.

[9] I. Slav, World's Helium Problem May Have Just Gotten Solved.https://oilprice.com/Energy/Energy-General/World s-Helium-Problem-May-Have-Just-Gotten-Solved.html.

[10] T. Torgersen and W. J. Jenkins, Helium isotopes in geothermal systems: Iceland, The Geysers, Raft River and Steamboat Springs, Geochimica et Cosmochimica Acta, Vol. 46, No. 5, 739-748, 1982. https://doi.org/10.1016/001 6-7037(82)90025-4.

[11] https://en.wikipedia.org/wiki/Aneutronic_fusion.

[12] https://www.esa.int/Our_Activities/Preparing_for_the_Futu re/Space_for_Earth/Energy/Helium-3_mining_on_the_lun ar_surface.

[13] B. Lowenstern, W. C. Evans, D. Bergfeld and A. G. Hunt, Prodigious degassing of a billion years of accumulated radiogenic helium at Yellowstone, Nature, Vol. 506, 355358, 2014. DOI: 10.1038/nature12992.

[14] E. Padrón, N. M. Peréz, P. A. Hernandez, H. Sumino, G. V. Melián, J. Barrancos, D. Nolasco, G. Padilla, S. Dionis, F. Rodriguez, I. Hernàndez, D. Calvo, M. D. Peraza and K. Nagao, Diffusive helium emissions as a precursory sign of volcanic unrest, Geology, Vol. 41, No 5, 539-542, 2013. DOI: https://doi.org/10.1130/G34027.1.

[15] Z. Jin and M. Bose, New clues to ancient water on Itokawa, Science Advances, Vol. 5, No. 5, 1-9, 2019. DOI: 10.1126/sciadv.aav8106.

[16] A. Williams, Scientists detect evidence of 'oceans worth' of water in earth's mantle, Astrobiology Magazine, 2014. https://www.astrobio.net/news-exclusive/scientists-detect-e vidence-oceans-worth-water-earths-mantle/.

[17] N/m2 - Newton per Square meter. Conversion calculator. https://www.convert-me.com/en/convert/pressure/nmsq.ht $\mathrm{ml} ? \mathrm{u}=\mathrm{nmsq} \& \mathrm{v}=1 \% 20378 \% 20020 \% 20000$.

[18] https://sciencing.com/density-temperature-lithosphere-2334 1.html.

[19] https://sciencestruck.com/asthenosphere-facts.

[20] https://www.engineeringtoolbox.com/dynamic-pressure-d_ 1037.html.

[21] Steam Tables, Thermopedia A-to-Z Guide to Thermodynamics, Heat \& Mass Transfer, and Fluids Engineering DOI: 10. 1615/ AtoZ. s.steam_tables http://the rmopedia.com/content/1150Begal.

[22] H. Petersen, The properties of helium: Density, specific heats, viscosity, and thermal conductivity at pressures from 1 to 100 bar and from room temperature to about $1800 \mathrm{~K}$, Risoe-R, No. 224, 1970. Risø National Laboratory. Denmark.

[23] https://sciencing.com/dominant-gas-volcano-eruptions-123 19033.html.

[24] Science Daily, 2018 https://www.sciencedaily.com/terms/a ntarctic_ice_sheet.htm. 
[25] G. M. Keating, and E. J. Prior, The winter helium bulge, in Space Research VIII, pp. 982-992, 1968. In A. P. Mitra, L. G. Jacchia, and W. S. Newman (Eds) Proceedings of the Tenth Cospar Plenary Meeting, Imperial College of Science and Technology, London, England, Jul. 24-29, 1967. North-Holland, Amsterdam.

[26] G. M. Keating, E. J. Prior, D. S. McDougal, and J. I. Nicholson, A critical evaluation of the OGO 6 helium model, in Space Research XV, pp. 273-278, 1974. In M. J. Rycroft (Ed) Proceedings of 17th Annual Cospar Meeting, Comm. on Space Res., Sao Paulo, Brazil June 17-July 1, 1974. North-Holland, Amsterdam.

[27] K. Mauersberger, W. E. Potter and D. C. Kayser, A direct measurement of the winter helium bulge, Geophysical Research Letters, Vol. 3, No. 5, 269-271, 1976. https://doi.org/10.1029/GL003i005p00269.

[28] P. Dockrill, Solar Wind Is Blasting Earth's Oxygen onto The Surface of the Moon, Science Alert, 31 Jan 2017. https://www.sciencealert.com/solar-wind-is-blasting-earths -oxygen-onto-the-surface-of-the-moon.

[29] C. A. Reber, D. N. Harpold, R. Horowitz, and A. E. Hedin, Horizontal distribution of helium in the Earth's upper atmosphere, Journal of Geophysical Research, Vol. 76, No. 7, 1845-1848, 1971. DOI: 10.1029/JA076i007p01845.

[30] E. K. Sutton, J. P. Thayer, W. Wang, S. C. Solomon, X. Liu, and B. T. Foster, A self-consistent model of helium in the thermosphere Journal of Geophysical Research: Space Physics, Vol. 120, 6884-6900, 2015. DOI: 10.1002/2015J A021223.

[31] T. Sharp, Atmosphere of the Moon, Science\&Astronomy, 2017. https://www.space.com/18067-moon-atmosphere.ht $\mathrm{ml}$.

[32] Helium Spotted in Moon's Wispy Atmosphere, 2012. https://www.space.com/17138-helium-moon-atmosphere-1 unar-discovery.html.

[33] https://en.wikipedia.org/wiki/Solar_neutrino\#cite_note-4.

[34] Why does the nuclear fusion reaction yield more energy than the nuclear fission reaction? https://www.physlink.com/ed ucation/askexperts/ae534.cfm

[35] I. de Pater and J. Lissauer, Planetary Sciences, Cambridge University Press, p. 309, 2001. ISBN: 0-521-48194.

[36] C. J. Allegre, B. Dupre and E. Lewin, Thorium/uranium ratio of the Earth, Chemical Geology, Vol. 56, No. 3-4, 219-227, 1986. DOI: 10.1016/0009-2541(86)90005-7.

[37] R. A. Kerr, At Long Last, Moon's Core 'Seen', Science, 2011, https://www.sciencemag.org/news/2011/01/long-last-moon s-core-seen.

[38] S. Muto and S. Morita, Determination of Iron Density at the Plasma Center Using Radial Profile of $\mathrm{FeK} \alpha$, Lines in LHD, Plasma and Fusion Research, Vol. 3, S1086, 2008. https://doi.org/10.1585/pfr.3.S1086.

[39] T. Sumner, Ancient moon's mega magnetic field explained, 2014.https://www.sciencenews.org/article/ancient-moon\% E2\%80\%99s-mega-magnetic-field-explained.

[40] Apollo 15 Mission, Science Experiments - Lunar Surface Magnetometer. https://www.lpi.usra.edu/lunar/missions/apollo/apollo_15/e xperiments/lsm/.

[41] F. K. Lutgens, E. J. Tarbuck and D. Tasa, Essentials of Geology 13th, Chapter 3, Matter and minerals, 2017, Pearson Education. ISBN: 978-0-13-444662-2

[42] A. Strahler and A. Strahler, Physical Geography, John Wiley et Sons, p. 347 and 350, 2002. ISBN: 0-471-23800-7.

[43] Thermal Conductivity - learn. https://www.new-learn.info/ packages/clear/thermal/buildings/building_fabric/propertie s/conductivity.html.

[44] K. Gladkov, Atomin energia (Energy of Atom, in Finnish), MIR Publishing Co, Moscow, 1983, p. 288.

[45] T. Lay, J. Hernlund and B. A. Buffett, Core-mantle boundary heat flow, Nature Geoscience, Vol. 1, 25-32, 2008 www.nature.com/naturegeoscience.

[46] E. C. Robertson, Thermal properties of rocks, Open-File Report 88-441, United States Department of the Interior, Geological Survey, Reston Virginia, 1988.

[47] Lord Kelvin (William Thomson), On the Secular Cooling of the Earth. Transactions of the Royal Society of Edinburgh, Vol. XXIII, 167- 169, 1864.

[48] Bassfeld Technology Transfer Geothermal power generation, 2009,https://static.aminer.org/pdf/PDF/000/244/989/syste ms_in_technology_transfer_introduction.pdf.

[49] N. M. W. Roberts, M. J. van Kranendonk, S. Parman and P. D. Clift, Continent formation through time, Geological Society, London, Special Publications, Vol. 389, 1-16, 2015 , https://doi.org/10.1144/SP389.13.

[50] G. Elert (Ed), The Physics Factbook, Speed of the Continental Plates 2001. https://hypertextbook.com/facts/1 997/ZhenHuang.shtml.

[51] Informative reading - The Earth (R.P - 3.1, 3.2). http://lectmania.ru/2x1b6.html.

[52] J. McClain, Ophiolites and the interpretation of marine geophysical data: How well does the ophiolite model work for the Pacific Ocean crust p 173-185. In Y. Dilek and S. Newcomb (Eds), Ophiolite concept and the evolution of geological thought, Special Paper 373, The Geological Society of America, 2003. ISBN: 0-8137-2376-6.

[53] A. G. Jones, MT and Reflection: An Essential Combination, Geophysical Journal International, Vol. 89, No. 1, 7-18, 1987. https://doi.org/10.1111/j.1365-246X.1987.tb04380.x.

[54] H. Jödicke, Water and graphite in the Earth's crust - An approach to interpretation of conductivity models, Surveys in Geophysics, Vol. 13, No. 4-5, 381-407, 1992. DOI: 10.1007/BF01903484.

[55] Caltech geophysicists gain new insights on Earth's coremantle boundary, $2003 \mathrm{https}$ ://www.caltech.edu/about/new s/caltech-geophysicists-gain-new-insights-earths-core-man tle-boundary-781.

[56] https://www.quora.com/What-is-the-distribution-of-volcano es-around-the-world.

[57] R. H. R. Stanley and W. J. Jenkins, Noble Gases in Seawater as Tracers for Physical and Biogeochemical Ocean 
Processes, pp. 55-79. In P. Burnard (Ed), The Noble Gases as Geochemical Tracers, Advances in Isotope Geochemistry, Springer-Verlag Berlin Heidelberg 2013 https://www.whoi.edu/cms/files/stanley2013noblegaschapt er_200544.pdf.

[58] R. E. Houtz and J. Ewing, Upper crustal structure as a function of plate age, Journal of Geophysical Research, Vol. 81, No. 14, 2490-2498, 1976. https://doi.org/10.1029/JB08 $1 \mathrm{i} 014 \mathrm{p} 02490$.

[59] E. E. Davis, D. S. Chapman, K. Wang, H. Villinger, A. T. Fischer, S. W. Robinson, J. Griegel, D. Pribnow, J. Stein and $\mathrm{K}$. Becker, Regional heat flow variations across the sedimented Juan de Fuca Ridge eastern flank constraints on lithospheric cooling and lateral hydrothermal heat transport, Journal of Geophysical Research, Vol. 101, No. B8, 17,675 $-17,688,1999$.

[60] J. L. Charlou, J. P. Donoval, P. Jean-Baptiste, A. Dapoigny and P. A. Rona, Gases and helium isotopes in high temperature solutions sampled before and after ODP Leg 158 drilling at TAG Hydrothermal Field $\left(26^{\circ} \mathrm{N}\right.$, MAR), Geophysical Research Letters, Vol. 23, No. 23, 3491-3494, 1996, https://doi.org/10.1029/96GL02141.

[61] R. S. Keir, A note on the fluxes of abiogenic methane and hydrogen from mid-ocean ridges, Geophysical Research Letters, Vol. 37, No. 24, 2010. https://doi.org/10.1029/201 0GL045362.

[62] T. Boschetti, G. Etiope and L. Toscani, Abiotic Methane in the Hyperalkaline Springs of Genova, Italy, Procedia Earth and Planetary Science, Vol 7, 248 - 251, 2013. https://doi.org/10.1016/j.proeps.2013.02.004.

[63] J. W. H. Chi and C. E. Landahl, Hydrogen Reactions with Graphite Materials at High Temperatures and Pressures, Nuclear Applications, Vol 4. No. 3, 159-169, 1968. (Published online 2017). https://doi.org/10.13182/NT68-A 26380.

[64] D. S. Mikhailenko, A.V. Korsakov, P. S. Zelenovskiy and A. V. Golovin, Graphite-diamond relations in mantle rocks: Evidence from an eclogitic xenolith from the Udachnaya kimberlite (Siberian Craton), American Mineralogist, Vol. 101, No 10, 2155-2167, 2016. https://doi.org/10.2138/am2016-5657.

[65] K. Hänninen, Ecologically Important Reactions and Phenomena in the Mesosphere between the Two Global Ozone Layers. Environment and Ecology Research Vol. 6, No. 5, 433-445, 2018. DOI: 10.13189/eer.2018.060504. http://www.hrpub.org.

[66] Properties of Earth's Interior. https://www.eiteachers.org/sit e/handlers/filedownload.ash $x$ ?moduleinstanceid=92\&datai $\mathrm{d}=500 \&$ FileName $=04 \% 20$ dynamic $\% 20$ crust $\% 20$ key $\% 20 \mathrm{r}$. pdf.

[67] H. N. Edmonds, Chemical Signatures from Hydrothermal Venting on Slow Spreading Ridges, Diversity of Hydrothermal Systems on Slow Spreading Ocean Ridges, (27-42), (2010). In P. A. Rona, C. W. Devey, J. Dyment, B. J. Murton (Eds), Diversity of Hydrothermal Systems on Slow Spreading Ocean Ridges. ISBN: 978-0-875-90478-8.

[68] B. Handwerk, Deepest Volcanic Sea Vents Found; "Like Another World", National Geographic News, 2010. https://news.nationalgeographic.com/news/2010/04/10041 2-worlds-deepest-undersea-volcanic-vents-hydrothermal/.

[69] What is a hydrothermal vent? https://oceanservice.noaa.gov /facts/vents. html.

[70] C. Munoz-Saez, A. Namiki, and M. Manga, Geyser eruption intervals and interactions: Examples from El Tatio, Atacama, Chile, Journal of Geophysical Research: Solid Earth, Vol. 120, 7490-7507, 2015. DOI: 10.1002/ 2015JB012364.

[71] https://en.wikipedia.org/wiki/Cretaceous.

[72] https://en.wikipedia.org/wiki/Antarctic_Plate.

[73] https://en.wikipedia.org/wiki/Neogene.

[74] First intact fossil of prehistoric whale discovered in Wadi Al-Hitan, IUCN, International Union for Conservation of Nature, 2015. https://www.iucn.org/content/first-intact-fos sil-prehistoric-whale-discovered-wadi-al-hitan

[75] Wadi Al- Hitan (Valley of the Whales) World Heritage Datasheet, 2005. Online available from https://yichuans.git hub.io/datasheet/output/site/wadi-al-hitan-whale-valley/.

[76] R. M. Ortiz, Osmoregulation in Marine Mammals, Journal of Experimental Biology Vol. 204, 1831-1844, 2001.

[77] https://en.wikipedia.org/wiki/Pyroclastic_flow.

[78] 2004 Indian Ocean tsunami: Facts, FAQs and how to help. https://www.worldvision.org/disaster-relief-news-stories/2 004-indian-ocean-tsunami-facts. 